\title{
Codification and Validation of Professional Development Questionnaire of Teachers
}

\author{
Fatemah Ayyoobi ${ }^{1}$, Hadi Pourshafei ${ }^{1}$ \& Ali Asgari ${ }^{1}$ \\ ${ }^{1}$ Faculty of Education and Psychology, University of Birjand, South Khorasan, Iran \\ Correspondence: Ali Asgari, Faculty of Education and Psychology, University of Birjand, South Khorasan, \\ Iran. E-mail: ali.asgari@birjand.ac.ir
}

Received: June 1, 2015 Accepted: July 11, 2015 Online Published: March 29, 2016

doi:10.5539/ies.v9n4p215 URL: http://dx.doi.org/10.5539/ies.v9n4p215

\begin{abstract}
Teacher in the educational system and the teaching-learning process, as a main leading should need to knowledge and professional skills. Therefore, evaluation of professional development is important. This study aims to design and modify Construction and Validation of professional development questionnaire of teachers. This research based on methodology and data collection procedure was descriptive-surveyed. The population consists of 400 teachers from high in Birjand in the academic year 2013-2014. A sample of 246 was estimated by Krejcie and Morgan. The instrument used in this study is a researcher's questionnaire of teachers' professional development. In order to assess the reliability and validity was used the content and construct validity by using of exploratory and confirmatory factor analysis and Cronbach's alpha. Results show that the questionnaire has good reliability and validity. According to the results of a factor analysis of the eight factors (components) were identified for professional development of teachers that explains a total of $54 / 69 \%$ of total variance. It can be concluded that the questionnaire would be a suitable tool for the professional development of teachers.
\end{abstract}

Keywords: validation, secondary teacher, reliability, professional development

\section{Background and Objectives}

Recently, education system is the most significant issue and draws the attentions of all people more than previous years. Human beings didn't find any area better than education system to encounter challenges and problems of different fields (Rouf, 2007). The education system is one of the most important social systems that its principal axis is educating and teaching human beings (Safi, 2009). Benefiting capabilities and skills of human resources, this system provides the ground for development of the society. Therefore, the evolution of this system can provide the ground for the evolution and development of other systems. The organization of education and training can fulfill educational goals by benefiting knowledge oriented and qualified teachers. So, it is necessary to develop qualifications of teachers (Kashani \& Rostampoor, 2011). As the professional development of teachers results in continual change of roles and responsibilities of the teachers and their knowledge in different field, it is important. Those teachers that reached to a certain level of development, have wider perspective regarding their society and by their professional life are active in schools and finally they will improve the students' performance (Toosi, 2001).

All these issues show the importance of the role and position of teachers in the education system. It also shows the commitments of teachers and this system. Among these commitments are the continual development of teachers and those who are involved in the educational system by updating their knowledge and experiences and cooperation with other organizations to enrich their qualifications (Hejazi et al., 2009). According to Delore (1997), the success of each education system depends on the development of teachers' capabilities. The Japanese also believe that qualification of each system depends on the development of teachers' skills. Therefore, teachers should update their knowledge according to changes of the world and their vocational development is necessary (Daneshpazhoo \& Frzad, 2006). So, researchers have indicated indices for vocational development of teachers. According to the office of Improvement of Quality and Strategy, components and standards of professional development of teachers should be prepared in a way that, in one hand enable teachers to understand the different needs of student in emotional, social and educational areas and in other hand, show the teachers' qualifications in knowledge, skills and attitude dimensions (Laei, 2012).

Many standards and indices are introduced for professional development of teachers including professional 
development standards of the Maryland University, Department of Education, Liberra et al. (2004) professional development standards in the New Jersey department of education. Education department of Maryland University divided professional standards into two separate categories: content and process. Content knowledge, high quality teaching, research based and family involvement and learning environment include in the former group and the database, participation, evaluation, designing and teacher learning include in the latter group. Department of education of Kentucky State introduced education planning and designing, creating learning atmosphere, teaching, assessment and making relationship, evaluation and learning, feedback, cooperation with colleagues and parents, activity toward professional development, content knowledge and applying educational technology as professional development standards for new teachers. Liberra et al. (2004) also indicated many standards for professional development of teachers, including thematic knowledge, development of human resources, different learners, planning and educational strategy, evaluation, learning environment, special needs, relations participation and professional development. A recent paper has developed a comprehensive tool for professional development based on the introduced standards and indices.

Professional development of teachers viewed as a source for updating knowledge and skills of teachers in different fields and provides a ground for teachers' behavioral change and also enables teachers to reach to a level of professional development. If opportunities for learning, knowledge and skill are provided in schools and classes, teachers' performances also will be improved (Khan \& Begum, 2012). Prerequisite for fulfilling this aim and achieving educational goal is evaluating professional development degree of teachers and identifying their strengths and weak points to strengthen their strength and improve their weak points. So, designing tools to fulfill these goals is necessary. So, in one hand, noting the importance of professional development and awareness regarding the degree of this professional development will help us to recognize the teachers' strengths and pitfalls and in other hand, lack of a comprehensive tool for assessment of the degree of professional development of teachers, induced the researcher to design a tool for this purpose. Therefore, the goal of this study is making and evaluating the teachers' professional development questionnaire.

\section{Method}

\subsection{Participants}

Recent project is a descriptive-survey. Population includes 569 high school teachers of Birjand city who were serving in 2013-2014 school year. The sample also is estimated by Krejcie and Morgan in Tables 2, 4, and 6.

\subsection{Instrument}

To design the questionnaire the researcher has used the indices of department of education in Maryland University, Librra et al. (2004) and professional development standards of new teachers of Kentucky State. Regarding the indices that these three groups have indicated, to design the teachers' professional development questionnaire, the researcher has designed items in Likert's 5 range questionnaire (very much, much, average, small, very small).

\section{Results}

Due to the fact that the researcher has designed the teachers' professional development questionnaire, to assess the validity of the teachers' professional development, in spite of the validity of content, the validity of structure (exploratory and confirmatory factor analysis) also is used. To conduct exploratory factor analysis, in the first step, Kaiser-Meyer-Olkin and Bartlett's test is used whose results are displayed in Table1.

Table 1. KMO and Bartlett's test

\begin{tabular}{lc}
\hline Bartlett's test of Sphericity for Professional Development \\
\hline KMO index & 0.943 \\
Chi-Square & 7.514 \\
Degree of freedom & 1081 \\
Level of significance & 0.001 \\
\hline
\end{tabular}

KMO index is between 1 and 0 and the more is near to 1 the more shows the adequacy of the sampling for analysis. In recent functional analysis, the result of KMO index for professional development variable is 0.943 that implies confirmation of functional analysis. Bartlett's test also shows suitability of data for factor analysis. If 
there is significant relation between items, correlation between them will also be significant (Ghiasvand, 2011). To conduct exploratory analysis, principal components are used.

Table 2. Items with their factor loadings

\begin{tabular}{llllllllll}
\hline Items & F1 & F2 & F3 & F4 & F5 & F6 & F7 & F8 \\
\hline $\begin{array}{l}\text { The teacher introduces applied knowledge } \\
\text { to student by dominating and }\end{array}$ & & & & & & & & \\
understanding the subject. & & & & & & & \\
\hline
\end{tabular}

The teacher creates enthusiasm in learners about the subjects that teaches them and 0.738 relates them to everyday life of students.

The teacher, increases students' skills such as critical and creative thinking in the 0.727 teaching process.

4. The teacher introduces specialized knowledge to students to enable students for answering ambiguities and solving problems.

0.754

5. To make discussions more applicable, the teacher tries to evaluate teaching material 0.656 continually.

6. The teacher's educational designing is in a way that makes knowledge and 662.0 information meaningful for students.

7. The teacher relates learning with primary knowledge, and families' 0.404 experiences.

8. The teacher provides patterns for student to teach skills, concepts and 0.516 thinking process.

9. The teacher, use learning and educational strategies that are suitable for 0.467 student learning.

10. The teacher knows that creating a suitable class environment is effective with students learning.

0.736

11. To manage the class, the teacher uses principles and strategies that encourage positive cooperation and goal oriented education.

12. The teacher is obliged to benefit them in teaching students effectively.

0.800

13. The teacher encourages students to cooperate with each other.

14. The teacher creates a positive and healthy atmosphere in the classroom.

15. The teacher updates the student skills and attitude by awareness about knowledge, skills and attitude.

\subsection{3}


16. To update student learning, schools cooperate with teachers.

17. Knowing the role of family, the teacher makes continual relation with parents.

18. The teacher asks parents, supervisors and family members to accept the role of a private teacher at home.

19. To enrich student learning and enforcing learning environment, the teacher uses parents and family experience.

20. The teacher consults with his or her colleague about issues related to school.

\subsection{4}

0.642

0.717

21. To teach better, the teacher use appropriate teaching aids.

512.0

22. Teacher use the views and opinions of other partners in order to integrate the different disciplines of knowledge stems (Interdisciplinary learning).

23. to connect with parent and colleagues, the teachers use electronic tolls such as email, weblog and ...

24. To increase teaching effectiveness and to increase his or her professional development, the teacher uses different educational technologies.

25. The teacher facilitates learning by using educational technology.

26. The teacher applies educational programs that need computer and other educational technologies.

27. The teacher spends lots of times for investigation and research.

518.0

28. The teacher follows the organization call for projects, especially projects that are 682.0 related to education.

29. The teacher interacts with the professors and researchers who are specialize in teaching discipline.

30. The teacher publishes the result of his or her research to inform others about what he or she has done.

31. The teacher is interested in action research projects related to work environment. He or she is also interested in workshops related to project subjects.

32. The teacher is aware of student learning out of school and tries to use their

2814.0
experiences in classroom learning. 
33. Teacher, design the lesson plans based on the needs and issues of student.

34. The teacher has teaching experiences that apply them to improve students' appropriate learning.

35. The teacher integrates knowledge, skills and content to provide intra-discipline learning opportunity for students.

36. The teacher uses different lesson plan according to curriculum subjects to upgrade student learning level.

37. The teacher's educational planning is according to knowledge and information of students.

38. The teacher evaluates his or her scientific performance during school year.

0.700

39. To improve learning process, the teacher uses the result of his evaluation as a factor to enforce changes.

40. The teacher uses different evaluation approaches to improve student educational advancements.

41. Coordinating with school's principals, the teacher poses the result of his evaluation to parents.

42. The teacher uses the result of achievement test to reform his or her teaching method and learning process.

43. The teacher has high expectation for learning.

44. The teacher considers individual differences when he or she is teaching.

45. The teacher is aware of students' cognitive, social, emotional differences in learning.

46. The teacher uses different views in teaching to consider students' differences.

47. The teacher tries to relate students' learning experiences in different courses (intra subject and integrated approach)

\begin{tabular}{lcccccccc}
\hline Eigenvalue & 19.57 & 2.92 & 2.08 & 1.81 & 1.53 & 1.49 & 1.19 & 1.08 \\
\hline Percentage of variance & 41.54 & 6.32 & 4.43 & 3.85 & 3.26 & 3.18 & 2.53 & 2.29 \\
\hline Cumulative percentage & 41.54 & 47.86 & 52.29 & 56.15 & 59.41 & 62.59 & 65.12 & 69.54 \\
\hline
\end{tabular}

Noting Table 2 the questions that had load factor more than 0.30 were chosen. Base on this, 8 factors identified for professional development questionnaire. The first factor (including 9 questions) is related to component of thematic knowledge. The second factor (including 6 questions) is related to factor of learning environment. The third factor (including 5 questions) is related to the component of cooperation. The forth factor (including 6 questions) is related to the component of educational technology. The fifth factor (including 5 questions) is 
related to the component of research base. The sixth factor (including 5 questions) is related to component of educational designing. The seventh factor (including 5 questions) is related to the component of evaluation. The eighth factor (including 5 questions) is related to component of human resource development. In the above table, the statistical indices of the teacher professional development questionnaire are also shown by main factors. Factors of 1 to 8 are more than 1 and totally define 69.54 percent of the total variance. After exploratory factor analysis, confirmative factor analysis will be performed.

Confirmative factor analysis considers the relation between observed variables (items or questions) and hidden variables in the questionnaire. For professional development questionnaire 50 items and 9 components is considered. In outcome model of factor analysis, total fitting of model, load factors and significance level of each will be considered (Kareshki, 2012) and factor loading higher than 0.30 will be accepted. To conduct confirmative factor analysis in first step, relation o each item with components of professional development questionnaire will be investigate. With $\mathrm{t}$ significance test also can understand significance of standard coefficients (load factors). If the flashes are red and $\mathrm{t}$ value is less than 2, statistical coefficients are not significant.

Table 3. First step factor analysis coefficient of the teachers' professional development questionnaire

\begin{tabular}{|c|c|c|c|c|c|}
\hline $\begin{array}{l}\text { Component of teachers' } \\
\text { development }\end{array}$ & professional & $\begin{array}{c}\text { Number of } \\
\text { item }\end{array}$ & $\begin{array}{c}\text { Factor } \\
\text { Loading }\end{array}$ & $\mathbf{T}$ & $\begin{array}{c}\text { Significant } \\
\text { level }\end{array}$ \\
\hline \multirow{9}{*}{ Thematic knowledge } & & 1 & 0.72 & & 0.001 \\
\hline & & 2 & 0.81 & 12.50 & 0.001 \\
\hline & & 3 & 0.67 & 12.69 & 0.001 \\
\hline & & 4 & 0.80 & 12.38 & 0.001 \\
\hline & & 5 & 0.77 & 11.85 & 0.001 \\
\hline & & 6 & 0.83 & 12.84 & 0.001 \\
\hline & & 7 & 0.66 & 10.13 & 0.001 \\
\hline & & 8 & 0.73 & 11.25 & 0.001 \\
\hline & & 9 & 0.75 & 11.65 & 0.001 \\
\hline \multirow{6}{*}{ Learning Environment } & & 10 & 0.81 & & 0.001 \\
\hline & & 11 & 0.82 & 14.97 & 0.001 \\
\hline & & 12 & 0.85 & 15.86 & 0.001 \\
\hline & & 13 & 0.86 & 16.06 & 0.001 \\
\hline & & 14 & 0.90 & 19.40 & 0.001 \\
\hline & & 15 & 0.75 & 13.28 & 0.001 \\
\hline \multirow{5}{*}{ Cooperation } & & 16 & 0.64 & & 0.001 \\
\hline & & 17 & 0.65 & 15.33 & 0.001 \\
\hline & & 18 & 0.81 & 12.94 & 0.001 \\
\hline & & 19 & 0.67 & 16.61 & 0.001 \\
\hline & & 20 & 0.80 & 13 & 0.001 \\
\hline \multirow{6}{*}{ Educational technology } & & 21 & 0.67 & & 0.001 \\
\hline & & 22 & 0.62 & 8.98 & 0.001 \\
\hline & & 23 & 0.64 & 9.28 & 0.001 \\
\hline & & 24 & 0.85 & 11.83 & 0.001 \\
\hline & & 25 & 0.90 & 12.42 & 0.001 \\
\hline & & 26 & 0.82 & 11.53 & 0.001 \\
\hline
\end{tabular}




\begin{tabular}{lllll}
\hline & 27 & 0.76 & & 0.001 \\
Research base & 28 & 0.82 & 13.20 & 0.001 \\
& 29 & 0.80 & 12.87 & 0.001 \\
Educational planning & 30 & 0.76 & 12.10 & 0.001 \\
& 31 & 0.73 & 11.54 & 0.001 \\
& 32 & 0.58 & 9.02 & 0.001 \\
\hline \multirow{3}{*}{ Evaluation } & 33 & 0.77 & & 0.001 \\
& 34 & 0.70 & 12.20 & 0.001 \\
& 35 & 0.88 & 13.34 & 0.001 \\
Development of human resources & 36 & 0.76 & 12.22 & 0.001 \\
& 37 & 0.80 & 13.06 & 0.001 \\
\hline & 38 & 0.82 & & 0.001 \\
& 39 & 0.86 & 15.91 & 0.001 \\
& 40 & 0.87 & 16.03 & 0.001 \\
& 41 & 0.64 & 10.73 & 0.001 \\
& 42 & 0.74 & 12.91 & 0.001 \\
\hline & 43 & 0.50 & & 0.001 \\
& 44 & 0.71 & 7.57 & 0.001 \\
& 45 & 0.80 & 7.97 & 0.001 \\
& 46 & 0.89 & 8.83 & 0.001 \\
& 47 & 0.82 & 8.06 & 0.001 \\
\hline
\end{tabular}

As it is shown in the above table, each load factor is composed of proper items and all $t$ coefficients are significant in 0.01 level. The second step of factor analysis is conducted on main components of professional development questionnaire.

Table 4. Results of step 2 confirmatory factor analysis of the teachers' professional development questionnaire

\begin{tabular}{lccc}
\hline Component of teachers' professional development & Factor Loading & $\mathbf{T}$ & Significant level \\
\hline Thematic knowledge & 0.86 & 11.27 & 0.001 \\
Environment & 0.79 & 11.75 & 0.001 \\
Cooperation & 0.80 & 9.26 & 0.001 \\
Educational technology & 0.75 & 9.47 & 0.001 \\
Research base & 0.77 & 10.66 & 0.001 \\
Educational planning & 0.81 & 11.30 & 0.001 \\
Development of human resources & $\mathbf{0 . 8 6}$ & $\mathbf{1 2 . 8 8}$ & $\mathbf{0 . 0 0 1}$ \\
\hline
\end{tabular}

The results of the second step of factor analysis also suggest that factor loads and $\mathrm{t}$ coefficient are very appropriate and are significant at 0.01 .

The Table 5 shows how each component of professional development relates to other component and how much is the relationship. The result shows that in whole, correlation coefficients of these components are higher than 0.40 and all of them are significant in a level less than 0.01 . To assess fitness of the teachers' professional development questionnaire, goodness of fit indices is used. Noting acquired fitness indices shows that the recent questionnaire has a good fitness. The Cronbach's alpha is used to assess reliability of the teachers' professional development questionnaire. 
Table 5. Correlation coefficients of teachers' professional development components

\begin{tabular}{lccccccccc}
\hline $\begin{array}{l}\text { Component of teachers' professional } \\
\text { development }\end{array}$ & $\mathbf{1}$ & $\mathbf{2}$ & $\mathbf{3}$ & $\mathbf{4}$ & $\mathbf{5}$ & $\mathbf{6}$ & $\mathbf{7}$ & $\mathbf{8}$ & $\mathbf{9}$ \\
\hline 1. Thematic knowledge & 1 & & & & & & & \\
2. Environment & 0.640 & 1 & & & & & & \\
3. Cooperation & 0.584 & 0.442 & 1 & & & & & \\
4. Educational technology & 0.579 & 0.432 & 0.627 & 1 & & & & \\
5. Research base & 0.511 & 0.466 & 0.559 & 0.614 & 1 & & & \\
6. Educational planning & 0.663 & 0.515 & 0.534 & 0.506 & 0.504 & 1 & & \\
7. Evaluation & 0.647 & 0.626 & 0.646 & 0.607 & 0.581 & 0.589 & 1 & \\
8. Development of human resources & 0.710 & 0.632 & 0.611 & 0.626 & 0.658 & 0.588 & 0.654 & 1 & \\
9. Professional development & 0.852 & 0.731 & 0.758 & 0.802 & 0.787 & 0.764 & 0.832 & 0.851 & 1 \\
\hline
\end{tabular}

* All components are significant in a level less than 0.01 .

Table 6. Fitting indices of (confirmative factor analysis) the teachers' professional development questionnaire

\begin{tabular}{ll}
\hline$\chi^{2} /$ DF & $\mathbf{2 . 4 8}$ \\
P & 0.001 \\
GFI & 0.69 \\
CFI & 0.97 \\
NFI & 0.95 \\
RMSEA & $\mathbf{0 . 0 7 8}$ \\
\hline
\end{tabular}

Table 7. Cronbach's alpha of the teachers' professional development questionnaire

\begin{tabular}{lc}
\hline $\begin{array}{l}\text { Components of the teachers } \\
\text { Alpha }\end{array}$ & Cronbach's professional development \\
\hline Educational planning & 0.84 \\
Thematic knowledge & 0.90 \\
Cooperation & 0.84 \\
Educational technology & 0.88 \\
Evaluation & 0.87 \\
Research based & 0.90 \\
Learning environment & 0.90 \\
Development of human resources & $\mathbf{0 . 8 6}$ \\
\hline
\end{tabular}

Noting the results of factor analysis and the observed reliability, we can infer that the teachers' professional development questionnaire can be used as a tool to assess the amount of the teachers' professional development in the next projects.

\section{Discussion and Conclusion}

Noting the result of recent project, we can infer that the recent questionnaire can be used as a proper tool to assess the amount of the teachers' professional development. To confirm validity of the teachers' professional development questionnaire, content and structure validity are used exploratory and confirmatory factor analysis. For content validity, university professors 'points of views are used to solve drawbacks. For validity of structure in first step, exploratory factor analysis and method of main component are used. Finally, 8 factors defined: learning environment, thematic knowledge, educational planning, research based, educational development, 
cooperation, and human resource development. Noting that the main goal of the teachers' professional development is improvement of student learning and performance, each component in a particular way provides the ground for fulfillment of this goal. Educational planning helps teachers to introduce subjects reasonably and comprehensively and facilitate achievement of educational goals (Poorshafei, 2013). If the teacher can create a peaceful and positive environment, involve students in teaching process, provide grounds for their development in different aspects by their support, they will be motivated for advancement. Concerning thematic knowledge, while teachers are familiar with basic concepts and specialized structure of knowledge, they will be able to provide learning experience for students and make these experiences meaningful (Liberra et al., 2004). Cooperation with parents and peers result in enriching students' learning by creating friendly and healthy relations (Liberra et al., 2004). Likewise, application of educational technology in class will result in students' learning. The teacher's awareness and mastery of the project cause the program to be effective theoretically and practically. Finally, identifying the strength and pitfall of the teachers needs evaluation. All these components provide a ground for teachers' development and improve students' performances.

Among these components, content of educational planning, thematic knowledge, development of human resources, and learning environment are tuned with indices of professional development of Liberra et al. (2004) in department of education in New Jersey. The content of evaluation and cooperation components are tuned with evaluation and learning reaction and cooperation with parents standards of department of education in Kentucky State. The content of research based is tuned with research based index of Maryland University of Education and the content of educational technology component is somehow tuned with the index of application of educational technology in Kentucky State (1999). The result of exploratory analysis shows that these factors in whole define 69.54 percent of total variance of the scores. In confirmative factor analysis outcome model also the indices of fitting of the model and load factors are appropriate and the t-statistic that is acquired in a significant test is meaningful in 0.01 level. The results of reliability tests also show that in all components Chronbach's alpha is more than 0.84 that is good and acceptable. Therefore, noting the results of factor analysis (exploratory and confirmative) and Chronbach's alpha we can conclude that the designed questionnaire is an appropriate tool for evaluating the degree of teachers' professional development.

\section{References}

Daneshpazhooh, Z., \& Farzad, V. (2006). Evaluation of professional skills of primary school teachers. Journal of educational Innovation, 135-170.

Giasvand, A. (2012). Application of statistics and SPSS software in data analysis. Tehran: Motefakeran publications.

Hejaz, S. Y., Pardakhtchi, M. H., \& Shahpasand, M. R. (2009). Approach of teachers' professional development. Tehran: Tehran University publication.

Kareshki, H. (2012). Relations of linear structures in Human sciences researches. Tehran: Avaye nor publications.

Kashani, M., \& Rostampur, M. (2013). Education the most vital tool in sustainable development. Social sciences, 67, 81- 89 .

Kentuky Educational Standards Board. (1999). Experienced Teacher Standards for Preparation \& Certification. Retrieved from http://www.kyepsb.net/teacherprep/expstandards.asp

Khan, B., \& Begum, S. (2012). Portfolio: A professional development and learning tool for teachers. International Journal of Social Science and Education, 2(2), 363-377.

Kronley, A., \& Handley, C. (2001). Framing the field: professional development in context. The finance project.

Laei, S. (2012). Teachers' development in educational systems. Procedia-Social and Behavioral Sciences, 47, 250-255. http://dx.doi.org/10.1016/j.sbspro.2012.06.647

Librera, W. L., Eyck, R. T., Doolan, J., Brady, J., \& Aviss-Spedding, E. (2004). New Jersey Professional Standards for Teachers and School Leaders. New Jersey Department of Education.

Maryland Department of Education. (2005). Teacher professional development standard. Retrieved from $\mathrm{http} / \mathrm{www} . \mathrm{mdk} 12 . \mathrm{org} / \mathrm{instruction} /$ professional development /teachers-standards.html

Poorshafei, H. (2013). Booklet of supervision and guidance, university of education and psychology. Birjend University.

Raoof, A. (2007). Principals and fundamentals of education (philosophy of education of teachers). Tehran: 
Arasbaran publications.

Safi, A. (2009). Organization and management in education. Tehran: Arasbaran.

Zolfaghari-Za' farani, R. (2005). Informational and communication technology in higher education. Management Development, 64, 40-45.

\section{Copyrights}

Copyright for this article is retained by the author(s), with first publication rights granted to the journal.

This is an open-access article distributed under the terms and conditions of the Creative Commons Attribution license (http://creativecommons.org/licenses/by/3.0/). 